\title{
Ensino Religioso: construção de uma proposta
}

PASSOS, J. D. Ensino Religioso: construção de uma proposta. São Paulo: Paulinas, 2007.

\section{Robson Stigar}

Mestre em Ciências da Religião pela Universidade Católica de São Paulo (PUC-SP), Curitiba, PR - Brasil, e-mail: robsonstigar@hotmail.com

Na obra Ensino Religioso: construção de uma proposta, de João Décio Passos, o autor procurou sistematizar a questão do Ensino Religioso (ER) no Brasil, dividindo-o em três modelos de Ensino Religioso.

O modelo Catequético é organizado e se sustenta na confecionalidade. Assim, no entender do autor, em todos os momentos históricos após o surgimento do Cristianismo, "a catequese era vista como construção, como uma prática escolar voltada para a formação das idéias corretas em oposição às idéias falsas" (p. 57) - (CNBB, Doc. 26, 8-13). Nesse modelo, os conteúdos ficam sob responsabilidade das igrejas e, com a confecionalidade, aparece o modelo pedagógico tradicional. Contudo, o risco dessa proposta é o proselitismo e a intolerância religiosa.

O modelo Catequético possui uma cosmovisão unirreligiosa, seu contexto político é a aliança entre Igreja e Estado, tem como fonte os conteúdos Doutrinais e seu método é a Doutrinação. Apresenta grande afinidade com a escola tradicional, seu objetivo é a expansão das igrejas, a responsabilidade é das confissões religiosas e, assim como o modelo Catequético, é grande o risco de proselitismo e intolerância.

O modelo Teológico possui uma cosmovisão plurirreligiosa, seu contexto político é a sociedade secular, sua fonte nasce da antropologia/ 
teologia plural e seu método é a indução. Tem possui grande afinidade com a escola nova, seu objetivo é a formação religiosa do cidadão, a responsabilidade é das confissões religiosas e possui um grande risco como uma catequese disfarçada. Esse modelo teológico

é adotado porque se trata de uma concepção de ER que procura uma fundamentação para além da confecionalidade estrita de forma a superar a prática catequética na busca de uma justificativa mais universal para a religião enquanto dimensão do ser humano e como um valor a ser educado (p. 60).

Essa cosmovisão representa uma nova forma de ver a religião, ou seja, supera a cosmovisão da cristandade medieval para buscar um argumento racional teológico. Esse modelo esteve presente nas escolas a partir do Concílio Vaticano II, usando como fundamento as modernas teologias. Assim, a teologia age como pressuposto que sustenta a convicção dos agentes e a própria motivação da ação, e a missão de educar é afirmada como um valor sustentado por uma visão transcendente do ser humano. Por conseguinte, a filosofia serve de apoio racional à teologia para pensar o Ensino Religioso.

O modelo das Ciências da Religião se apoia especificamente na Epistemologia e por isso se distingue dos outros dois modelos:

consiste em tirar as decorrências legais, teóricas e pedagógicas da afirmação do ER como uma área de conhecimento... Tratase de reconhecer, sim, a religiosidade e a religião como dados antropológicos e socioculturais que devem ser abordados no conjunto das demais disciplinas escolares por razões cognitivas e pedagógicas (p. 65).

A base teórica e metodológica desse modelo remete às Ciências da Religião, possui uma cosmovisão transreligiosa, seu contexto político é a sociedade secularizada, sua fonte é as Ciências da Religião e seu método é a indução. Possui afinidade com a epistemologia atual, seu objetivo é a educação do cidadão, a responsabilidade dele é a comunidade científica e do Estado, e o risco é a neutralidade científica.

Segundo Passos, o modelo mais indicado éo das Ciências da Religião; contudo, é preciso considerar as dificuldades na formação dos professores e na estruturação dos modelos políticos em nível superior. Por tudo isso,

as reflexões apresentadas desenvolveram-se a partir da idéia de três pressupostos de ER, dois a serem superados nas práticas 
escolares, o da fé e da religiosidade, e um último a ser construído, o da educação do cidadão (p. 133).

Assim, entende-se que o ponto de partida precisa ser o fenômeno religioso do qual se constitui a sociedade como tal. Por último, é preciso enfrentar os desafios acadêmicos da formação dos docentes e, principalmente, conseguir apoio financeiro para estruturar programas de estudos mais avançados na área de ER no Brasil como um todo.

Segundo o autor, a Lei n. 9.475, de julho de 1997 (BRASIL, 1997), abriu caminho para a afirmação epistêmica e pedagógica de uma nova área de ensino dentro da escola publica, o Ensino Religioso. Contudo, existem problemas porque a definição de um plano de ensino e um programa para formação de docentes se torna difícil porque o Ensino Religioso se mantêm como campo aberto, vácuo de legislação especifica reguladora.

Assim, para o autor, "a formação básica do cidadão aguarda a formação básica dos docentes do Ensino Religioso para que esta disciplina possa efetivar-se como prática educativa legítima e comum no currículo e na vida dos educandos" (p. 23).

O Ensino Religioso precisa se estruturar a partir da base epistemológica, com "conteúdos que podem vir do senso comum, de tradições religiosas ou do acúmulo das pesquisas científicas, no caso das ciências” (p. 27).

Assim, precisamos distinguir dois tipos de ensino: o que reproduz conhecimento e o que produz conhecimento. Com efeito, o primeiro modo de ensino se fundamenta na tradição oral ou escrita e a segunda forma, no meio sistemático da escola. Para tanto, o autor entende que o Ensino Religioso ajuda a decodificar valores e tradições.

Neste sentido, por epistemologia do ER entendemos a sua base teórica e metodológica, enquanto área de conhecimento específica que assume a religião como objeto de estudos produzindo sobre este resultados compressivos que normalmente são credenciados como ciência (p. 28).

Contudo, percebe-se que existe uma carência histórica no estudo do Ensino Religioso. Esse modo de ensino da espiritualidade ou de religiosidade precisa estar ancorado em fundamentos epistemológicos sólidos. E preciso considerar que a religião é ensinada nas diversas áreas da vida e, por isso, a escola também é um espaço para tal prática. Assim, “entendemos o Ensino Religioso como o ensino da religião na escola sem o pressuposto da fé, mas 
com o pressuposto pedagógico" (p. 32). Isto é, o estudo da religião é tão importante quanto a educação do cidadão.

Tal ensino estaria, portanto, fundado na factualidade e na relevância do preceito religioso para a vida social, fazendo parte de um projeto mais amplo que não coloca a priori a religiosidade dos sujeitos como algo a ser educado, mas, antes, os próprios sujeitos, independentemente de suas adesões de fé (p. 33).

Esse estudo da religião deve envolver um preparo dos conteúdos curriculares a serem ensinados. Em síntese, o autor entende que "a educação necessita de uma base moral, que por sua vez requer um fundamento religioso" (p. 36). Com efeito, existe uma necessidade de montar uma estrutura para o ensino de Ensino Religioso.

Desse modo, o Ensino Religioso remete à tarefa epistemológica sua fundamentação para o âmbito das ciências e seu ensino nas escolas. Segundo o autor, apesar da religião acompanhar o processo educacional, ela sempre esteve, na Idade Moderna, fora desse jogo racional e pedagógico. Por conseguinte,

a procura por uma base epistemológica pode hoje contribuir com a superação de modelos científico-modernos centrados numa visão um tanto especializada da realidade, na busca de modelos mais abrangentes que respondam à educação dos sujeitos em sua totalidade de relações e dimensões (p. 39).

Desse modo, justifica-se o intento dos defensores do Ensino Religioso que afirmam a necessidade de um lugar para esta disciplina no currículo escolar:

educar é conduzir pelos caminhos do conhecimento na busca da autonomia intelectual e política. Portanto, ciência, ensinoaprendizagem e cidadania formam o tripé de toda ação educativa, isso traduzido em ação social (p. 41).

É nessa dinâmica que o Ensino Religioso participa e tem seu significado dentro da escola, e é nesse processo de ensinar e aprender que aparece o ER. Por conseguinte, "'a epistemologia sustentadora do ER, assim como as demais disciplinas, pretende resgatar a totalidade da vida humana na sua singularidade individual e social e nas suas variadas dimensões" (p. 42). Assim, uma das funções do Ensino Religioso é a crítica ao conhecimento tecnicista que instrumentaliza o conhecimento no domínio 
de algum aspecto restrito da realidade: "a crítica ao positivismo que coloca a ciência como a única versão da verdade e a crítica à neutralidade das ciências como abordagem definitiva da realidade" (p. 43). Isso significa que quando estudamos a religião, ele leva em si o confronto com as diferentes formas de modelos e compartilhamento da busca de valores. A religião faz parte dessa dinâmica social de ensino porque leva uma enorme quantidade de valores, e isso é o que faz do Ensino Religioso uma disciplina no currículo escolar.

Segundo o autor, o valor religioso contribui para a formação dos valores dos cidadãos e, mais do que isso, representa uma ajuda na convivência harmônica do homem. Assim, "a escola deve assumir isso em sua tarefa educativa como lugar de reflexão sobre a realidade a partir das referências oferecidas pelas ciências sobre os mais diversos elementos que dão forma à sociedade" (p. 46). Portanto, a tarefa de educar o indivíduo sobre a religião é de todos, bem como sua religiosidade.

Partindo dessa dinâmica e desse entendimento da realidade, Passos considera que "se poderá construir um cidadão livre e responsável. Se este não for mais religioso, o que poderá ocorrer, deverá ser mais ético e consciente da força da religião na vida pessoal e individual" (p. 46).

Contudo, segundo o autor, é preciso que existam modelos de ensino religioso para que se evite o excesso de conteúdo desnecessário. Dentro dos modelos propostos, deve se buscar o mais adequado ou os elementos que melhor comporiam o quadro do ensino religioso.

\section{Referência}

BRASIL. Presidência da República. Lei n. 9.475/97, de 22 de julho de 1997. Alteração, normas, correlação, facultatividade, disciplina escolar, religião, estabelecimento de ensino, ensino fundamental, território nacional, competência, sistema de ensino, fixação, conteúdo, disciplina escolar, religião. Diário Oficial [da] República Federativa do Brasil, Brasília, Congresso Nacional, 23 jul. 1997. Coluna 2, p. 15824. Disponível em: <http://www6.senado.gov.br/legislacao/ ListaNormas.action?tipo_norma=LEI>. Acesso em: 22/12/2008.

Recebido: 01/02/2010

Received: 02/01/2010

Aprovado: $10 / 03 / 2010$

Approved: 03/10/2010 